\title{
Prediction of Welding Deformation and Residual Stress of a Thin Plate by Improved Support Vector Regression
}

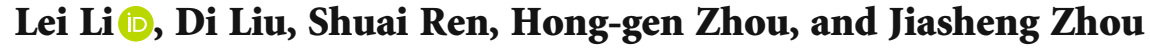 \\ School of Mechanical Engineering, Jiangsu University of Science and Technology, Zhenjiang 212003, China \\ Correspondence should be addressed to Lei Li; lilei0064@sina.com
}

Received 25 September 2020; Revised 11 November 2020; Accepted 15 February 2021; Published 3 March 2021

Academic Editor: Jian Chen

Copyright (C) 2021 Lei Li et al. This is an open access article distributed under the Creative Commons Attribution License, which permits unrestricted use, distribution, and reproduction in any medium, provided the original work is properly cited.

\begin{abstract}
Thin plates are widely utilized in aircraft, shipbuilding, and automotive industries to meet the requirements of lightweight components. Especially in modern shipbuilding, the thin plate structures not only meet the economic requirements of shipbuilding but also meet the strength and rigidity requirements of the ship. However, a thin plate is less stable and prone to destabilizing deformation in the welding process, which seriously affects the accuracy and performance of the thin plate welding structure. Therefore, it is beneficial to predict welding deformation and residual stress before welding. In this paper, a thin plate welding deformation and residual stress prediction model based on particle swarm optimization (PSO) and grid search(GS) improved support vector regression (PSO-GS-SVR) is established. The welding speed, welding current, welding voltage, and plate thickness are taken as input parameters of the improved support vector regression model, while longitudinal and transverse deformation and residual stress are taken as corresponding outputs. To improve the prediction accuracy of the support vector regression model, particle swarm optimization and grid search are used to optimize the parameters. The results show that the improved support regression model can accurately evaluate the deformation and residual stress of butt welding and has important engineering guiding significance.
\end{abstract}

\section{Introduction}

Welding is a process of forming permanent connection by heating or pressing the material of the workpiece to achieve the combination of atoms. Compared with riveted parts, castings, and forgings, welding products have the advantages of being lightweight, having a simple process, having low production cost, and having strong adaptability [1]. The welding technology is an indispensable processing method, which is widely used in aerospace, atomic energy, electronic technology, shipbuilding, construction, marine engineering, transportation and machinery manufacturing, and other industrial sectors [2-4]. Various welding deformations can occur in ship structures due to uneven heat and cold, local uncoordinated plastic strains, and welding residual stresses. Welding deformation and stress are important factors that affect the quality of hull construction and have a great impact on the welding performance, structural strength, toughness, aesthetics, and accuracy control of ship construction. This phenomenon is more obvious in thin plate welding [5].
Therefore, the research on prediction and control of welding deformation and residual stress of a thin plate has a very important engineering application value.

With the development of numerical analysis theory, the finite element method (FEM) has been adopted by many studies to predict welding deformation and residual stress. Since Ueda and Yamakawa analyzed the welding thermal stress and residual stress of butt and fillet welds by the thermo-elastic-plastic FEM, many researchers continued to develop this method for calculating the temperature, residual stress, and deformation [6]. At present, the FEM is also used in different welded joints and simple structure welds [7-9]. Liang et al. studied the welding deformation of aluminum alloy sheets by experiment and the TEP finite element method. The out-of-plane deformation predicted by the finite element method is in good agreement with the measured results [10]. Deng et al. used the finite element method to predict the welding deformation and residual stress of a thin plate and further investigated the influence of external constraints on welding deformation [11-14]. Shen et al. 
TABLE 1: The chemical composition and mechanical properties of AH32.

\begin{tabular}{lccccccc}
\hline $\mathrm{C}$ & $\mathrm{Mn}$ & $\mathrm{Si}$ & $\mathrm{S}$ & $\mathrm{P}$ & Yield strength (MPa) & Tensile strength (MPa) & Elongation (\%) \\
\hline$\leq 0.18$ & $0.70 \sim 1.60$ & $0.10 \sim 0.50$ & $\leq 0.04$ & $\leq 0.04$ & 315 & $440 \sim 590$ & 22 \\
\hline
\end{tabular}

derived the stress amplification factor considering the influence of the preliminary deformation of the thin plate on the basis of the modified thick plate calculation formula. Then, with the traditional specification of the calculation, results were compared to verify the feasibility and effectiveness of the formula $[15,16]$. Hu et al. established a finite element model to study the lateral bow and direction residual stress of s690 cold-formed thin-walled steel [17].

In many cases, the deformation and residual stress are simulated by FEM and then verified by experimental measurement. However, the FEM takes a long time and requires high computer performance and the implementation of experimental measurement needs high condition and cost [5]. Therefore, it is meaningful to setup a model which can predict the deformation and residual stress before welding. In the past decade, various forecasting models have emerged. $\mathrm{He}$ and Li applied a support vector machine (SVM) to quantitatively evaluate the welding quality [18]. Tian and Luo established an intelligent prediction model for welding deformation of T-joint fillet weld based on combinatorial optimization algorithms [19]. Katherasan et al. adopted the artificial neural network (ANN) algorithm to determine the approximate optimal value of welding process parameters and then used particle swarm optimization (PSO) to optimize the process parameters [20]. Edwin and Kumanan discussed the application of the evolutionary fuzzy support vector regression model in welding residual stress prediction [21]. Ansaripour et al. uses the ANN algorithm and multiobjective optimization algorithm to minimize deformation and residual stress during submerged arc welding [22]. Rong et al. analyzed the influence of the weld profile on angle distortion and predicted the angle distortion of gapless tungsten inert gas arc weld using the neural network [23]. Mathewa et al. established the prediction model of residual stress distribution of austenitic stainless steel girth-welded pipe by using the artificial neural network [24]. Sagai et al. successfully used process parameters to predict mechanical properties by using the stochastic and nonlinear parallel machining neural network model [25]. Das et al. used the machine learning algorithm to predict the welding residual stress of stainless steel [26]. Mathew et al. used the fuzzy neural network (FNN) to predict the welding residual stress of pressure vessels and achieved good results [27]. Koo et al. proposed a prediction model of residual stress in the welding area based on improved support vector regression [28].

In this paper, the corresponding inherent deformation and residual stress are obtained under different values of voltage, current, speed, and plate thickness. Based on the experimental data, a prediction model of welding deformation and residual stress of a thin plate based on particle swarm optimization and grid search-improved support vector regression (PSO-GS-SVR) was established. Then, the predicted results of the PSO-GS-SVR model are compared with
TABLE 2: Welding parameters.

\begin{tabular}{lcccccc}
\hline Parameter & Units & Notation & & & & \\
\hline Voltage & $\mathrm{V}$ & $U$ & 25 & 27 & 29 & 31 \\
Current & $\mathrm{A}$ & $I$ & 180 & 190 & 200 & 210 \\
Speed & $\mathrm{mm} / \mathrm{s}$ & $S$ & 5 & 6 & 7 & 8 \\
Plate thickness & $\mathrm{mm}$ & $T$ & 3 & 4 & 5 & 6 \\
\hline
\end{tabular}

the experimental results. The results show that there is a high degree of consistency between the predicted results and the experimental measurements. The research shows that the improved support regression model can more accurately evaluate the welding deformation and residual stress of butt welding than the original model.

The rest of this paper is arranged as follows. Section 2 shows that the deformation and residual stress corresponding to different welding parameters are obtained by experiments. Section 3 introduces the related algorithm theory. In Section 4, an improved prediction method of support vector regression is established. The optimized SVR model was evaluated by comparing the prediction results with the experimental results, which is shown in Section 5. Finally, in Section 6, this paper is summarized and the future research direction is pointed out.

\section{The Experimental Procedure}

In this experiment, two similar $\mathrm{V}$-joint planes of $300 \times 150$ $\mathrm{mm}$ plates were selected. The workpiece material is AH32, which is high-strength steel. The chemical composition and mechanical properties are shown in Table 1. Due to the small welding deformation and residual stress, $\mathrm{CO}_{2}$ gas-shielded welding is adopted, which is especially suitable for thin plate welding. The process parameters, namely, voltage $(U)$, current $(A)$, speed $(S)$, and plate thickness $(T)$, are varied in the range of $25-31 \mathrm{~V}, 180-210 \mathrm{~A}, 5-8 \mathrm{~mm} / \mathrm{s}$, and $3-6 \mathrm{~mm}$, respectively. The detailed combination of the test process parameter design is shown in Table 2. Then, the transverse deformation and longitudinal deformation of welding are measured by a coordinate measuring machine (CMM). The residual stress of the workpiece was measured by X-ray diffraction.

2.1. Measurement of Deformation. In order to accurately measure the welding deformation value, the deformation results of $\mathrm{V}$-shaped groove components after welding were measured by a coordinate measuring machine. The welding component is placed on the measuring platform, and the measuring platform is used as the zero-value point of bending deformation. Then, the transverse deformation and longitudinal deformation are obtained by measuring the marked measuring points on the workpiece surface step by step. Transverse deformation is the deformation 


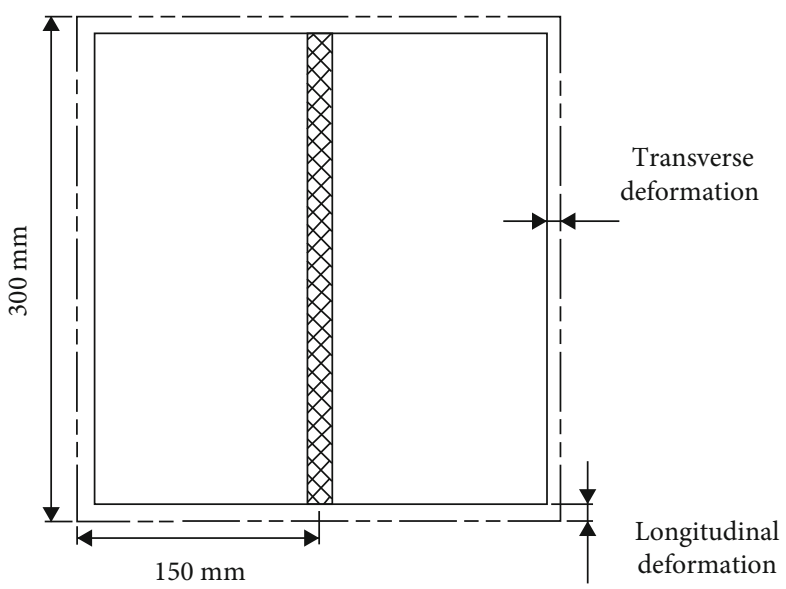

(a)

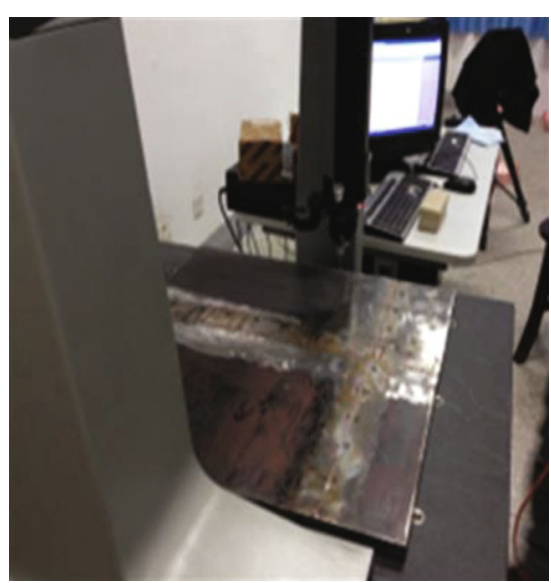

(b)

FIgURE 1: Welding deformation measurement. (a) Longitudinal and transverse deformation. (b) Experimental measurements.
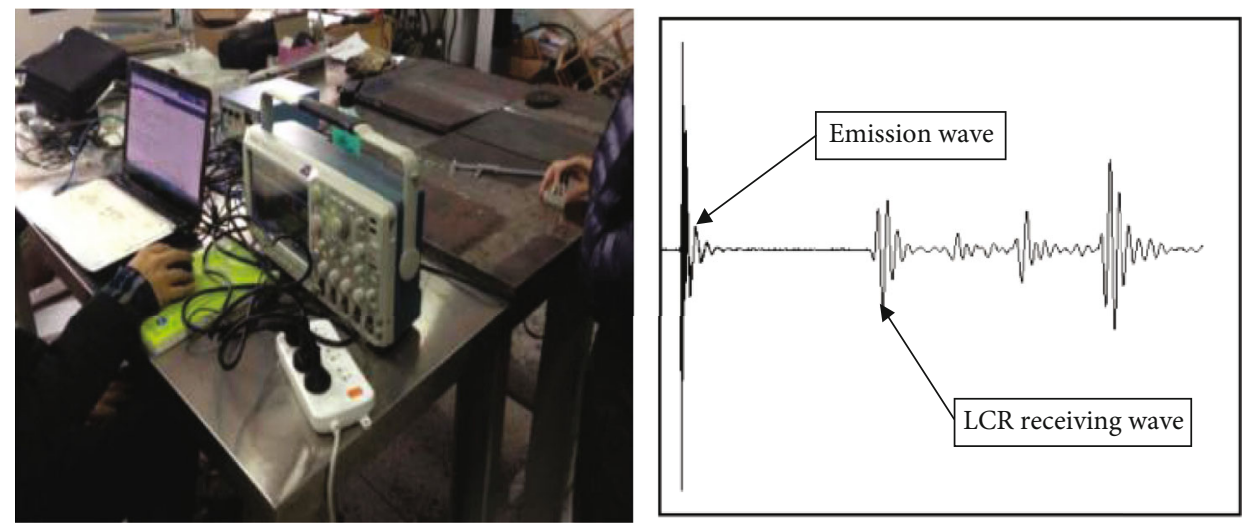

FIGURE 2: Measurement process of residual stress.

perpendicular to the direction of the weld; longitudinal deformation is the deformation parallel to the direction of the weld, as shown in Figure 1(a). The deformation measurement process is shown in Figure 1(b).

2.2. Measurement of Residual Stress. At present, there are many methods to measure welding residual stress. According to the different forms of residual stress measurement, it can be divided into destructive testing and nondestructive testing (NDT) methods $[29,30]$. Nondestructive testing has been widely used for its advantages of not damaging components, such as magnetic measurement, ultrasonic measurement, and X-ray diffraction measurement [31-38]. In this paper, the ultrasonic method is selected for measurement. Because the residual stress perpendicular to the weld direction has a great influence on the structural strength, the point perpendicular to the weld direction on the half-width line of the workpiece is taken as the residual stress measurement point $[39,40]$. Figure 2 shows the measurement process of residual stress.

2.3. Experimental Dataset. Through the above experimental measurement, this study consists of 24 groups of different experimentally measured datasets. The dataset is divided into two parts. The left half is for the different $U, I, S$, and $T$ process parameters. The right half is the deformation values and residual stresses corresponding to the different process parameters. All the experimental results are shown in Table 3.

\section{The Related Algorithm Theory}

3.1. Support Vector Regression. To solve the problem of pattern recognition, the support vector machine (SVM) is proposed by Vapnik [41]. Later, the insensitive loss function is introduced and applied to the regression estimation of nonlinear systems, which forms support vector regression (SVR). The basic theory of SVR is to map the dataset to a high-dimensional space in the way of nonlinear transformation and then regress in this space to fit a continuous function to minimize the loss function. The goal is to find an optimal classification surface that minimizes the error of all training data, in order to achieve better fitting performance and generalization ability for unknown samples. The SVR has many unique advantages in solving a small sample, nonlinear, 
TABLE 3: Experimental results.

\begin{tabular}{|c|c|c|c|c|c|c|c|}
\hline $\begin{array}{l}\text { Experiment } \\
\text { number }\end{array}$ & $\begin{array}{c}\text { Voltage } \\
\text { (V) }\end{array}$ & $\begin{array}{l}\text { Current } \\
\text { (A) }\end{array}$ & $\begin{array}{l}\text { Speed } \\
(\mathrm{mm} / \mathrm{s})\end{array}$ & $\begin{array}{l}\text { Plate thickness } \\
\qquad(\mathrm{mm})\end{array}$ & $\begin{array}{c}\text { Transverse } \\
\text { deformation }(\mathrm{mm})\end{array}$ & $\begin{array}{c}\text { Longitudinal } \\
\text { deformation }(\mathrm{mm})\end{array}$ & $\begin{array}{c}\text { Residual stress } \\
(\mathrm{MPa})\end{array}$ \\
\hline 1 & 25 & 180 & 5 & 3 & 0.531 & 0.441 & 61.35 \\
\hline 2 & 25 & 190 & 6 & 4 & 0.445 & 0.403 & 69.78 \\
\hline 3 & 25 & 200 & 7 & 5 & 0.372 & 0.344 & 79.67 \\
\hline 4 & 25 & 210 & 8 & 6 & 0.313 & 0.283 & 217.08 \\
\hline 5 & 27 & 180 & 6 & 5 & 0.441 & 0.463 & 65.78 \\
\hline 6 & 27 & 190 & 5 & 6 & 0.398 & 0.421 & 62.23 \\
\hline 7 & 27 & 200 & 8 & 3 & 0.341 & 0.354 & 117.36 \\
\hline 8 & 27 & 210 & 7 & 4 & 0.372 & 0.333 & 76.27 \\
\hline 9 & 29 & 180 & 7 & 6 & 0.476 & 0.461 & 265.80 \\
\hline 10 & 29 & 190 & 8 & 5 & 0.455 & 0.411 & 183.03 \\
\hline 11 & 29 & 200 & 5 & 4 & 0.539 & 0.431 & 70.23 \\
\hline 12 & 29 & 210 & 6 & 3 & 0.518 & 0.386 & 84.98 \\
\hline 13 & 31 & 180 & 8 & 4 & 0.493 & 0.463 & 89.23 \\
\hline 14 & 31 & 190 & 7 & 3 & 0.548 & 0.454 & 62.82 \\
\hline 15 & 31 & 200 & 6 & 6 & 0.536 & 0.401 & 283.97 \\
\hline 16 & 31 & 210 & 5 & 5 & 0.579 & 0.385 & 143.63 \\
\hline 17 & 25 & 190 & 5 & 3 & 0.523 & 0.412 & 89.67 \\
\hline 18 & 25 & 210 & 7 & 3 & 0.329 & 0.312 & 119.90 \\
\hline 19 & 27 & 180 & 8 & 4 & 0.413 & 0.423 & 92.27 \\
\hline 20 & 27 & 200 & 7 & 4 & 0.402 & 0.373 & 81.89 \\
\hline 21 & 29 & 180 & 5 & 5 & 0.461 & 0.489 & 74.56 \\
\hline 22 & 29 & 210 & 7 & 5 & 0.440 & 0.345 & 158.02 \\
\hline 23 & 31 & 190 & 8 & 6 & 0.530 & 0.414 & 325.09 \\
\hline 24 & 31 & 210 & 6 & 6 & 0.535 & 0.368 & 260.82 \\
\hline
\end{tabular}

high-dimensional pattern recognition, and so on. It has been gradually applied to the prediction of welding deformation and residual stress. The learning ability and generalization ability of SVR are determined by the regularization coefficient $C$ and the related parameters of kernel function. The basic model is as follows [42]:

$$
f(x)=\omega \cdot \varphi(x)+b,
$$

where $\varphi(x)$ represents the nonlinear mapping of the input sample space to the feature space, $\omega$ is the weight coefficient, and $b$ is the offset term. The loss function is obtained by minimizing $\omega$ and $b$.

$$
R(x)=\frac{1}{2}\|\omega\|^{2}+C\left(\sum_{i=1}^{l} \mu_{i}\left(\xi_{i}+\xi_{i}^{\prime}\right)\right),
$$

bound by formula (3) as follows:

$$
\left\{\begin{array}{c}
f\left(x_{i}\right)-y_{i} \leq \varepsilon+\xi_{i}{ }^{\prime}, \\
y_{i}-f\left(x_{i}\right) \leq \varepsilon+\xi_{i}, \\
\xi_{i}, \xi_{i}{ }^{\prime} \geq 0 \\
\quad i=1,2, \cdots, l
\end{array}\right.
$$

where $l$ represents the total of training data, $C$ denotes the regularization coefficient, $\varepsilon$ is the insensitive coefficient, $\xi_{i}$ and $\xi_{i}{ }^{\prime}$ are the relaxation variables, and $(1 / 2)\|\omega\|^{2}$ is the confidence risk of the model. The SVR model is as follows:

$$
f(x)=\sum_{i=1}^{l}\left(a_{i}-a_{i}^{\prime}\right) K\left(x, x_{i}\right)+b,
$$

where the coefficient $a_{i}-a_{i}{ }^{\prime}$ is not equal to zero and is solved using the quadratic planning technique, the corresponding training data vectors are called support vectors, and $K\left(x, x_{i}\right)$ is the kernel function.

For different kernel functions, the types and quantities of parameters that need to be determined are different. Since the RBF kernel function has the advantages of less parameters and nonlinear prediction, the RBF function is selected as the kernel function of the SVR regression model. The expression of the RBF kernel function is shown in formula (5) as follows:

$$
K\left(x, x_{i}\right)=\exp \left(-\frac{\left\|x-x_{i}\right\|}{2 g^{2}}\right)
$$


where $g$ is the width parameter of the RBF kernel function, $x$ is any input sample vector, and $x_{i}$ is the center of the Gaussian RBF kernel function.

Therefore, it is important to find the optimal regularization parameter $C$ and the width of kernel function $g$.

3.2. Particle Swarm Optimization. Particle swarm optimization (PSO), developed by Kennedy and Eberhart, is an evolutionary computing technology derived from the study of bird predation behavior [43]. Particle swarm optimization (PSO) has a faster convergence speed and less adjustable parameters, so it is easy to implement. Therefore, it is often used in combination with other algorithms to optimize parameters. The specific algorithm flow is as follows:

Step 1. Initialize the particle swarm optimization. Set the maximum iteration number, the maximum velocity of particles $v_{\max }$, the position of the space $x_{i}$, the particle swarm optimization modulus $N$, and the initial flight speed $v_{i}$.

Step 2. Define the moderation function. First, calculate the adaptation value for each particle and find the individual optimal solution from it. Then, the global optimal value of a group is found from the individual optimal solution. Finally, the global optimal value is compared with the historical global optimal value and updated.

Step 3. The velocity and position of particles are updated as shown in formula (6) as follows:

$$
\begin{gathered}
v_{i}=\omega * v_{i}+c_{1} * r_{1} * i\left(p_{i d}-x_{i}\right) \\
+c_{2} * r_{1} *\left(p_{g d}-x_{i}\right), \quad i=1,2, \cdots, N, \\
x_{i}=x+v_{i}, \quad i=1,2, \cdots, N,
\end{gathered}
$$

where $c_{1}, c_{2}$ is the learning factor, $\omega$ is the inertia factor, $r_{1}$, $r_{2} \in(0,1)$ is the random value, $p_{i d}$ is the particle local optimal position, and $p_{g d}$ is the global optimal position.

Step 4. If the global optimal solution position satisfies the minimum limit or reaches the maximum iteration number, it will be the output to the particle with optimal fitness.

Because particle swarm optimization has the advantages of good global search ability, fast convergence speed, and less adjustable parameters, it can find the most suitable regularization parameters $C$ and RBF parameter $g$ of SVR more quickly and efficiently.

3.3. Grid Search. Grid search (GS) is widely used in support vector machines for parameter search optimization [44]. It can perform comprehensive search in parallel, and its computational complexity is very prominent. Since the RBF function is chosen as the kernel function of SVR, only the optimal values of $C$ and $g$ had to be determined. This method maps all combinations of these two parameters to a 3D grid, and then, solves all solutions and obtains the optimal combina-

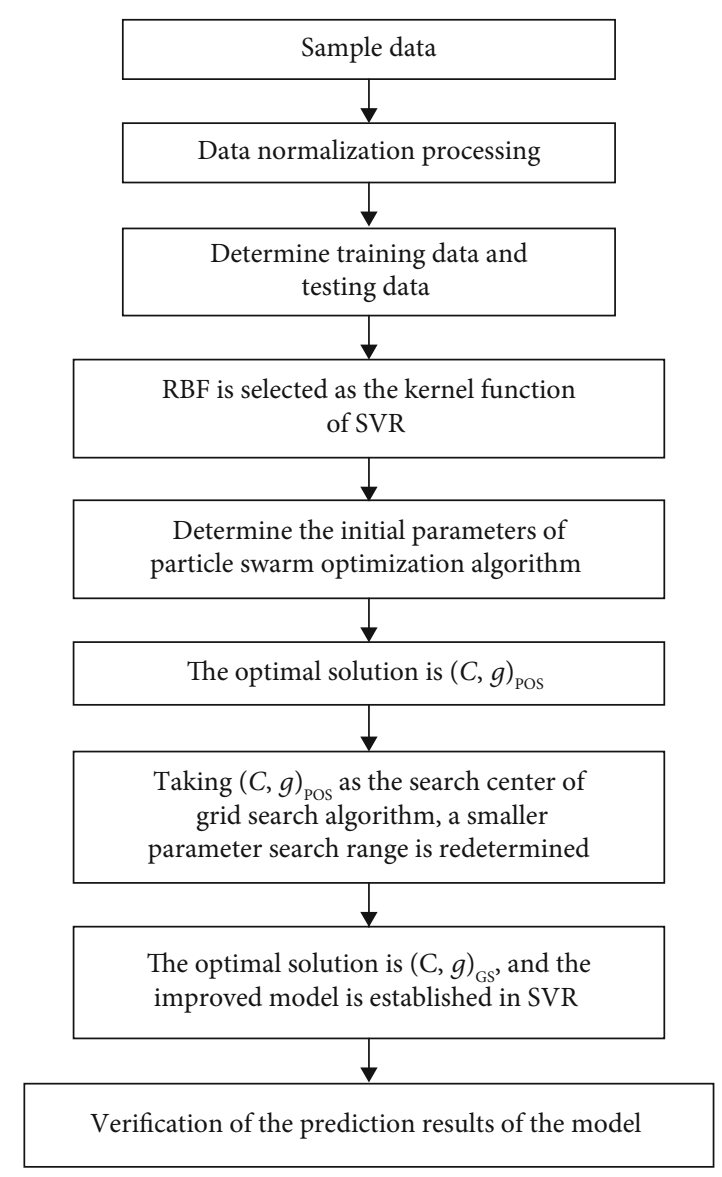

FIgURE 3: The main flow of the PSO-GS-SVR model.

tion. Finally, the groups of $C$ and $g$ with the highest prediction accuracy of cross-validation of the training set are selected as the optimal parameter combination.

\section{The SVR Model Improved by the PSO and GS}

In this paper, an improved SVR model is proposed by exploiting the advantages of particle swarm optimization and grid search. In the early stage of the algorithm, the particle swarm optimization (PSO) is used for fast rough search in a large range, and then, the population optimal solution (not necessarily the global optimal one) is found. Taking the optimal solution of the population as the initial position, the coordinate system grid of relevant parameters is established, and then, the grid search (GS) is used to search a small step between the initial positions of a small cell, which can avoid a large number of previous invalid operations. In this paper, an improved support vector regression (PSO-GS-SVR) deformation prediction model is developed to predict the weld deformation and residual stresses in butt joints with weld speed, weld current, weld voltage, and plate thickness as inputs. The improved support vector regression prediction model consists of three main steps, namely, data preprocessing, prediction model implementation, and resultant prediction validation. The main flow of the proposed PSO-GS-SVR model is shown in Figure 3. 


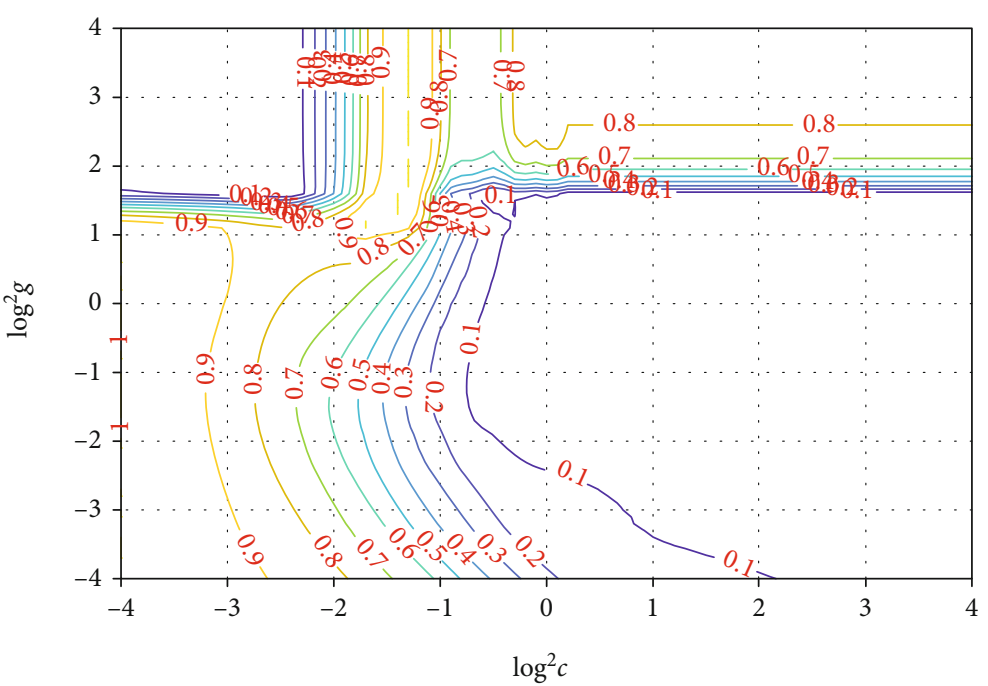

(a)

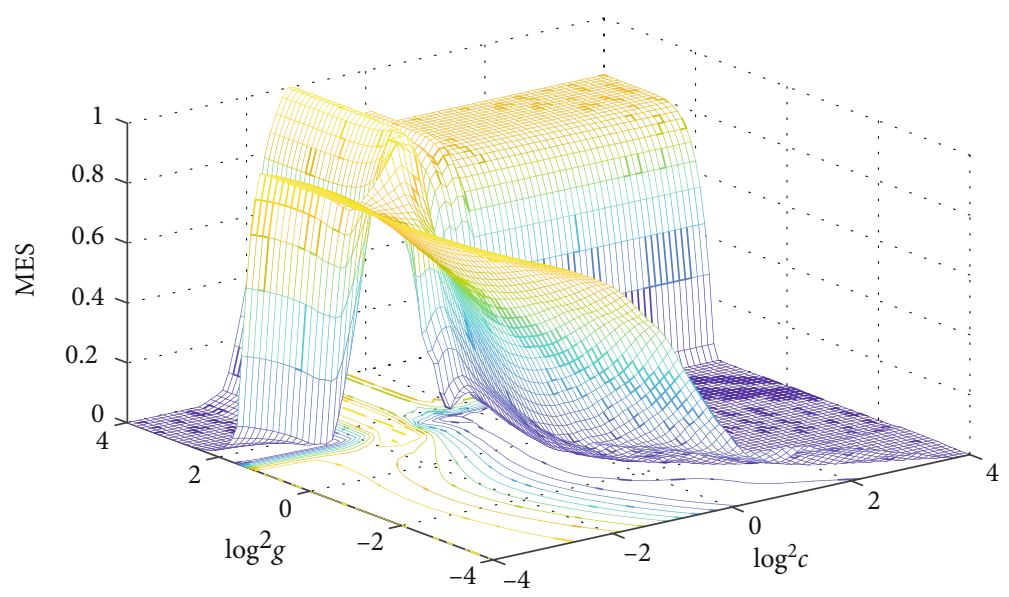

(b)

FIgUre 4: Result chart of refined parameter selection. (a) Contour map. (b) 3D view plot.

\subsection{Data Preprocessing}

4.1.1. Data Normalization Processing. In order to eliminate the difference between dimensions, the sample data is normalized and mapped to $[0,1]$; the formula is as follows:

$$
\bar{x}=\frac{x-x_{\min }}{x_{\max }-x_{\min }} .
$$

4.1.2. Data Classification. The first 16 groups of data in Table 1 are used as training data, and the remaining 8 groups of data are used as test data.

4.2. Implementation of the Model. The main implementation steps are as follows:

(1) Set initial boundary conditions. Particle swarm optimization (PSO) is used to optimize the width $g$ and regularization coefficient $C$ of the kernel function. The parameters involved include population size $m$, inertia weight $w$, acceleration constants $c_{1}$ and $c_{2}$, maximum velocity $V_{\max }$, and maximum algebra $G_{\max }$. It is determined that the population number is 20 and the population derivation algebra is 100. Because this is the first fast search, the search interval of parameter $C$ can be set a little larger. Select the interval of two parameters as a learning factor. After all the preparatory work is completed, the first parameter optimization process can be started

(2) After getting the optimal parameters of PSO, it is marked as $(3.151,0.624)_{\mathrm{POS}}$. According to the optimal parameters, the grid of the coordinate system is established with the parameters as the central starting point and the second fine mesh search of the small step length is carried out. Since the step size of traditional grid search method is generally 0.1 , the step size is set to 0.05 in the small step fine search. Set the inter cell as $\left[2^{-4}, 2^{4}\right]$. After a small step search, the optimal solution is obtained as shown in Figure 4, which is recorded as $(3.732,0.144)_{\mathrm{ms}}$ 


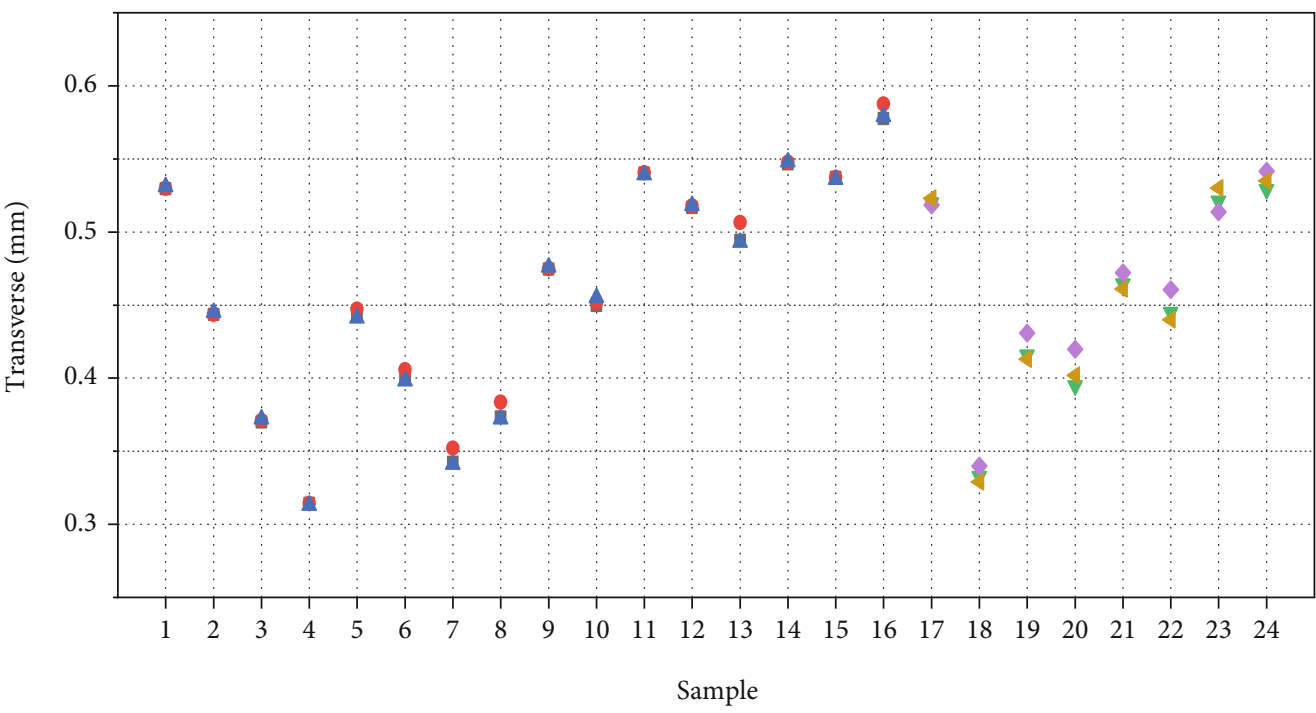

- Training data predicted by POS-GS-SVR

$\checkmark$ Testing data predicted by POS-GS-SVR

- Training data predicted by SVR

- Testing data predicted by SVR

\ Training data by measurement

$\triangleleft$ Testing data by measurement

(a)

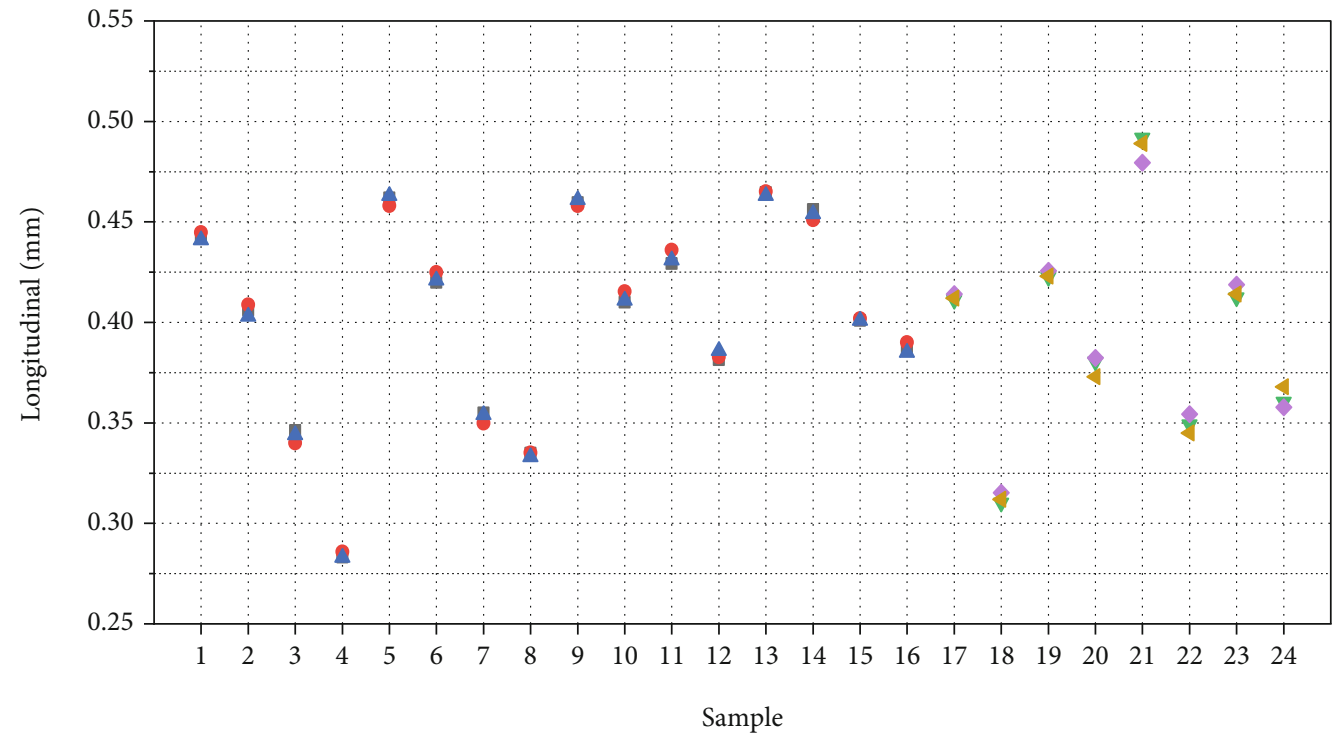

- Training data predicted by POS-GS-SVR

- Training data predicted by SVR

- Training data by measurement $\checkmark$ Testing data predicted by POS-GS-SVR

Testing data predicted by SVR

$\triangleleft$ Testing data by measurement

(b)

FIGURE 5: Comparison of predicted and experimental deformation values. (a) Transverse deformation. (b) Longitudinal deformation.

(3) The optimal parameters are substituted into the SVR model and its kernel function to establish the prediction model of improved support vector regression

\section{Results and Discussion}

In this section, the particle swarm optimization (PSO) and grid search(GS) optimized SVR model was evaluated by comparing the prediction results with the experimental results. Meanwhile, the accuracy of the optimized SVR model and the nonoptimized SVR model is also compared.

The prediction results of welding deformation and residual stress are shown in Figures 5 and 6, respectively. Among them, the black " $\square$ " is the training data predicted by the PSOGS-SVR model, the red "๑" represents training sample data predicted by the SVR model, the blue " $\mathbf{\Delta}$ " stands for the 


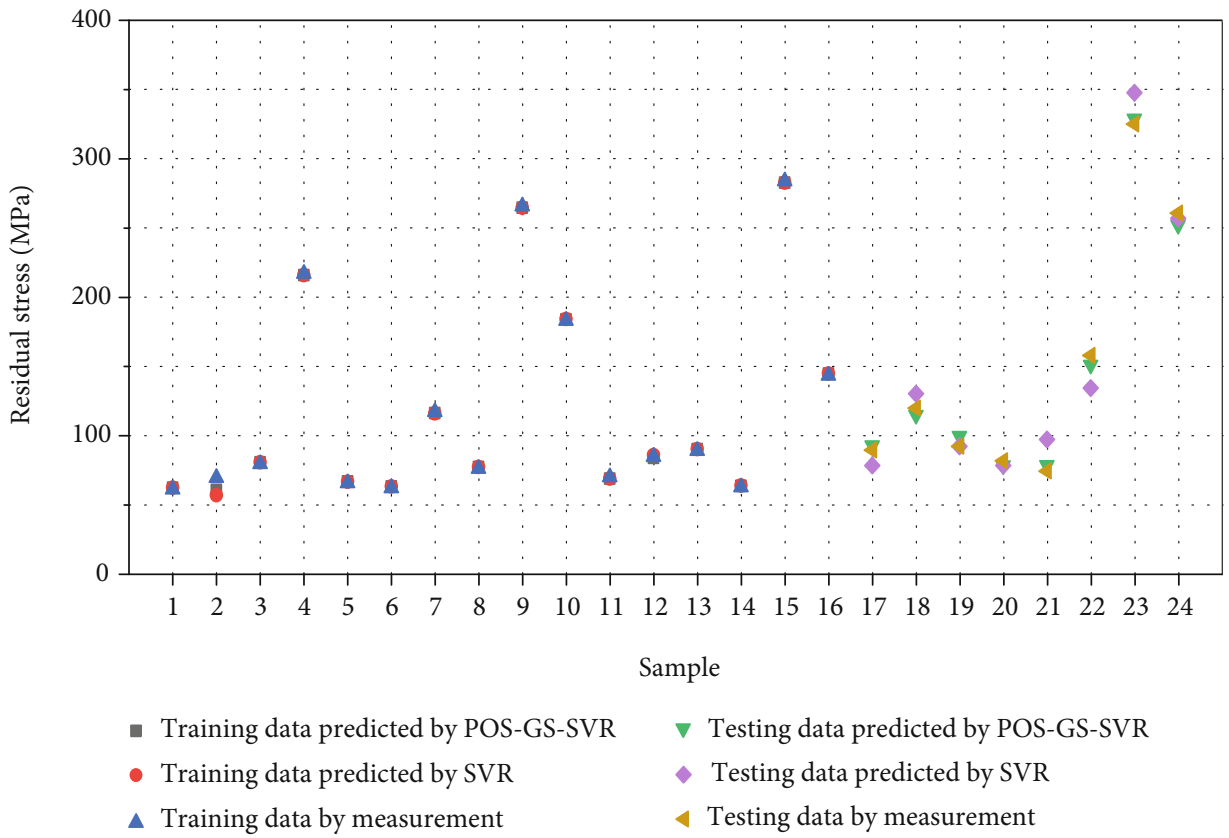

FIGURE 6: Comparison of predicted and experimental residual stress values.

TABLE 4: Prediction performance evaluation of the PSO-GS-SVR model.

\begin{tabular}{lcccccccccc}
\hline & & \multicolumn{3}{c}{ Transverse deformation } & \multicolumn{2}{c}{ Longitudinal deformation } & \multicolumn{2}{c}{ Residual stress } \\
& & $R^{2}$ & MAPE (\%) & MSE & $R^{2}$ & MAPE (\%) & MSE & $R^{2}$ & MAPE (\%) & MSE \\
\hline \multirow{2}{*}{ PSO-GS-SVR } & Training & 0.9931 & 0.5324 & 0.00001 & 0.9911 & 1.1496 & 0.00005 & 0.9967 & 1.9183 & 6.2346 \\
& Testing & 0.9677 & 1.2437 & 0.00004 & 0.9763 & 2.2527 & 0.00014 & 0.9745 & 4.3015 & 32.3187 \\
\multirow{2}{*}{ SVR } & Training & 0.9281 & 1.5391 & 0.00010 & 0.9450 & 3.7545 & 0.00023 & 0.9809 & 2.2783 & 11.4254 \\
& Testing & 0.8619 & 4.2559 & 0.00044 & 0.9064 & 5.8612 & 0.00043 & 0.8939 & 9.9153 & 115.3360 \\
\hline
\end{tabular}

training data of experimental measurement, the green " $\nabla$ " means the testing data predicted by the PSO-GS-SVR mode, the violet " $\diamond$ " denotes the testing data predicted by the SVR model, and the yellow " $\varangle$ " indicates the testing data of experimental measurement. When the PSO-GS-SVR model is used, there is a small difference between the predicted values of weld deformation (as shown in Figure 5) and residual stress (as shown in Figure 6) and the experimental values. Conversely, the predictions of the SVR model are more inaccurate. In conclusion, the proposed PSO-GS-SVR model can improve the prediction accuracy.

In order to further evaluate the prediction performance of the model, we choose three indexes: coefficient of determination $\left(R^{2}\right)$, mean absolute percentage error (MAPE), and mean square error (MSE). These formulas are as follows:

$$
\begin{aligned}
R^{2} & =\frac{\sum_{i=1}^{n}\left(y \wedge_{i}-\bar{y}_{i}\right)^{2}}{\sum_{i-1}^{n}\left(y_{i}-\bar{y}_{i}\right)^{2}}, \\
\mathrm{MAPE} & =\frac{1}{n} \sum_{i=1}^{n}\left(\left|\frac{\widehat{y}_{i}-y_{i}}{y_{i}}\right|\right) \times 100 \%, \\
\mathrm{MSE} & =\frac{1}{n} \sum_{i=1}^{n}\left(y_{i}-y \wedge_{i}\right)^{2},
\end{aligned}
$$

where $\hat{y}_{i}$ and $y_{i}$ denote the predicted values and the experimental values and $\bar{y}_{i}$ represents the mean value of experimental data. $n$ is the number of samples.

The statistical results shown in Table 4 give the $R^{2}$, MAPE, and MSE of deformation and residual stress. Combined with Figures 5 and 6, the two models are consistent with the overall trend of experimental data. However, further comparison between $R^{2}$, MAPE, and MSE shows that the PSO-GS-SVR model is superior to the SVR model in all three indicators, no matter the testing data or training data. The coefficient of determination approaches is close to 1 , indicating a very high degree of a match existing between the predicted values and experimental values. The value of MSE can evaluate the change degree of data. The MSE value tends to be 0 , which means that the prediction model has good accuracy. The MAPE value is very small, indicating that the model is stable. Therefore, the proposed PSO-GS-SVR model is feasible to predict the deformation and residual stress of butt welding of thin plates.

\section{Conclusion}

This paper studies the development of particle swarm optimization and grid search-optimized SVR model for welding 
deformation and residual stress of butt joint sheets, and the conclusion is as follows:

(1) The improved support vector regression model was developed for the prediction of welding deformation and residual stress of butt welding

(2) The transverse deformation, longitudinal deformation, and residual stress corresponding to different values of welding voltage, welding current, welding speed, and plate thickness were measured by experiments

(3) The experimentally obtained measurements are used to train the particle swarm and grid search-improved support vector machine model, which can predict the weld deformation and residual stress well. The results show that the PSO-GS-SVR model has excellent generalization capability

(4) Through the comparison of the three indicators, the PSO-GS-SVR model has better prediction accuracy than the SVR. It provides an effective method to predict welding deformation and residual stress of a thin plate

The current research object is simple butt welding. Considering the diversity of welded joints, our next research work is deformation prediction of a complex welding structure.

\section{Data Availability}

All the data used to support the findings of this study are included within the article.

\section{Conflicts of Interest}

The authors declare that they have no conflicts of interests.

\section{Acknowledgments}

This work was supported by the Special Funding Project for Key Technologies of Ship Intelligence Manufacturing from the MIIT of China under Grant MC-201704-Z02.

\section{References}

[1] H. Wei, Y. Zhang, L. Tan, and Z. Zhong, "Energy efficiency evaluation of hot-wire laser welding based on process characteristic and power consumption," Journal of Cleaner Production, vol. 87, pp. 255-262, 2015.

[2] D. Deng, H. Murakawa, and W. Liang, "Numerical simulation of welding distortion in large structures," Computer Methods in Applied Mechanics \& Engineering, vol. 196, no. 45-48, pp. 4613-4627, 2007.

[3] Q. Zhou, Y. Wang, S. K. Choi, L. Cao, and Z. Gao, "Robust optimization for reducing welding-induced angular distortion in fiber laser keyhole welding under process parameter uncertainty," Applied Thermal Engineering, vol. 129, pp. 893-906, 2018.

[4] Y. Rong, G. Mi, J. Xu, Y. Huang, and C. Wang, "Laser penetration welding of ship steel EH36: a new heat source and appli- cation to predict residual stress considering martensite phase transformation," Marine Structures, vol. 61, pp. 256-267, 2018.

[5] M. S. Choobi, M. Haghpanahi, and M. Sedighi, "Prediction of welding-induced angular distortions in thin butt-welded plates using artificial neural networks," Computational Materials Science, vol. 62, pp. 152-159, 2012.

[6] Y. Ueda and T. Yamakawa, "Analysis of thermal elastic-plastic stress and strain during welding by finite element method," Transactions of the Japan Welding Society, vol. 2, no. 2, pp. 186-196, 1971.

[7] Y. Lee, H. Jeong, K. Park, Y. Kim, and J. Cho, "Development of numerical analysis model for resistance spot welding of automotive steel," Journal of Mechanical Science and Technology, vol. 31, no. 7, pp. 3455-3464, 2017.

[8] C. Li, D. Fan, X. Yu, and J.-k. HUANG, "Residual stress and welding distortion of $\mathrm{Al} /$ steel butt joint by arc-assisted laser welding-brazing," Transactions of Nonferrous Metals Society of China, vol. 29, no. 4, pp. 692-700, 2019.

[9] Z. Lei, J. Zou, D. Wang et al., "Finite-element inverse analysis of residual stress for laser welding based on a contour method," Optics \& Laser Technology, vol. 129, p. 106289, 2020.

[10] W. Liang, H. Murakawa, and D. Deng, "Estimating inherent deformation in thin-plate Al-alloy joint by means of inverse analysis with the help of cutting technique," Advances in Engineering Software, vol. 99, pp. 89-99, 2016.

[11] D. Deng and H. Murakawa, "Prediction of welding distortion and residual stress in a thin plate butt- welded joint," Computational Materials Science, vol. 43, no. 2, pp. 353-365, 2008.

[12] D. Deng, Y. Zhou, T. Bi, and X. Liu, "Experimental and numerical investigations of welding distortion induced by $\mathrm{CO}_{2}$ gas arc welding in thin-plate bead-on joints," Materials \& Design (1980-2015), vol. 52, pp. 720-729, 2013.

[13] D. Deng, H. Murakawa, and N. Ma, "Predicting welding deformation in thin plate panel structure by means of inherent strain and interface element," Science and Technology of Welding and Joining, vol. 17, no. 1, pp. 13-21, 2012.

[14] D. Deng, X. Liu, J. He, and W. Liang, "Investigating the influence of external restraint on welding distortion in thin-plate bead-on joint by means of numerical simulation and experiment," The International Journal of Advanced Manufacturing Technology, vol. 82, no. 5-8, pp. 1049-1062, 2016.

[15] W. Shen, Y. Qiu, L. Xu, and L. Song, "Stress concentration effect of thin plate joints considering welding defects," Ocean Engineering, vol. 184, pp. 273-288, 2019.

[16] W. Shen, Y. Qiu, C. Li, Y. Hu, and M. Li, "Fatigue strength evaluation of thin plate butt joints considering initial deformation," International Journal of Fatigue, vol. 125, pp. 85-96, 2019.

[17] Y. Hu, K. Chung, H. Ban, and D. A. Nethercot, "Investigations into residual stresses in 6990 cold-formed circular hollow sections due to transverse bending and longitudinal welding," Engineering Structures, vol. 219, p. 110911, 2020.

[18] K. He and X. Li, “A quantitative estimation technique for welding quality using local mean decomposition and support vector machine," Journal of Intelligent Manufacturing, vol. 27, no. 3, pp. 525-533, 2016.

[19] L. Tian and Y. Luo, "A study on the prediction of inherent deformation in fillet-welded joint using support vector machine and genetic optimization algorithm," Journal of Intelligent Manufacturing, vol. 31, no. 3, pp. 575-596, 2020. 
[20] D. Katherasan, J. V. Elias, P. Sathiya, and A. N. Haq, "Simulation and parameter optimization of flux cored arc welding using artificial neural network and particle swarm optimization algorithm," Journal of Intelligent Manufacturing, vol. 25, no. 1, pp. 67-76, 2014.

[21] R. D. J. Edwin and S. Kumanan, "Evolutionary fuzzy SVR modeling of weld residual stress," Applied Soft Computing, vol. 42, pp. 423-430, 2016.

[22] N. Ansaripour, A. Heidari, and S. A. Eftekhari, "Multi-objective optimization of residual stresses and distortion in submerged arc welding process using genetic algorithm and harmony search," Proceedings of the Institution of Mechanical Engineers Part C-Journal of Mechanical Engineering Science, vol. 234, no. 4, pp. 862-871, 2020.

[23] Y. Rong, Y. Huang, G. Zhang, Y. Chang, and X. Shao, "Prediction of angular distortion in no gap butt joint using BPNN and inherent strain considering the actual bead geometry," International Journal of Advanced Manufacturing Technology, vol. 86, no. 1-4, pp. 59-69, 2016.

[24] J. Mathewa, R. J. Moatb, S. Paddea, M. E. Fitzpatrick, and P. J. Bouchard, "Prediction of residual stresses in girth welded pipes using an artificial neural network approach," International Journal of Pressure Vessels and Piping, vol. 150, pp. 89-95, 2017.

[25] F. B. A. Sagai, R. E. Raj, and M. C. Mabel, "Prediction of shear and tensile strength of the diffusion bonded AA5083 and AA7075 aluminium alloy using ANN," Materials Science and Engineering A-Structural Materials Properties Microstructure and Processing, vol. 692, pp. 1-8, 2017.

[26] D. Das, A. K. Das, D. K. Pratihar, and G. G. Roy, "Prediction of residual stress in electron beam welding of stainless steel from process parameters and natural frequency of vibrations using machine-learning algorithms," Proceedings of the Institution of Mechanical Engineers Part C-Journal of Mechanical Engineering Science, vol. 203-210, pp. 189-196, 2020.

[27] J. Mathew, J. Griffin, M. Alamaniotis, S. Kanarachos, and M. E. Fitzpatrick, "Prediction of welding residual stresses using machine learning: comparison between neural networks and neuro-fuzzy systems," Applied Soft Computing, vol. 70, pp. 131-146, 2018.

[28] Y. D. Koo, K. H. Yoo, and M. G. Na, "Estimation of residual stress in welding of dissimilar metals at nuclear power plants using cascaded support vector regression," Nuclear Engineering \& Technology, vol. 49, no. 4, pp. 817-824, 2017.

[29] K. Simmen, B. Buch, A. Breitbarth, and G. Notni, "Nondestructive inspection system for MAG welding processes by combining multimodal data," Quantitative Infrared Thermography Journal, pp. 1-17, 2019.

[30] S. Hong, Y. P. Wu, J. H. Wu et al., "Microstructure and cavitation erosion behavior of HVOF sprayed ceramic-metal composite coatings for application in hydro-turbines," Renewable Energy, vol. 164, pp. 1089-1099, 2021.

[31] Y. X. Qiao, Y. P. Chen, L. L. Li et al., "Corrosion Behavior of a Nickel-Free High-Nitrogen Stainless Steel With Hydrogen Charging," JOM, 2021.

[32] L. L. Yang, M. H. Chen, J. L. Wang et al., "Microstructure and composition evolution of a single-crystal superalloy caused by elements interdiffusion with an overlay NiCrAlY coating on oxidation," Journal of Materials Science \& Technology, vol. 45, pp. 49-58, 2021.

[33] Y. X. Qiao, D. K. Xu, S. Wang et al., "Effect of hydrogen charging on microstructural evolution and corrosion behavior of Ti-
4Al-2V-1Mo-1Fe alloy," Journal of Materials Science \& Technology, vol. 60, pp. 168-176, 2021.

[34] H. L. Zhou, F. L. Fu, Z. X. Dai, Y. X. Qiao, J. Chen, and W. Liu, "Effect of laser power on microstructure and micro-galvanic corrosion behavior of a 6061-T6 aluminum alloy welding joints," Metals, vol. 11, no. 1, p. 3, 2021.

[35] Y. Suzuki, H. Yamada, and K. Ikushima, “Tensile-stress dependence of magnetic hysteresis properties measured by the acoustically stimulated electromagnetic response in steel," IEEE Transactions on Ultrasonics Ferroelectrics and Frequency Control, vol. 1, no. 1, p. 99, 2019.

[36] Y. Qiao, J. Huang, D. Huang et al., "Effects of laser scanning speed on microstructure, microhardness and corrosion behavior of laser cladding Ni45 coatings," Journal of Chemistry, vol. 2020, Article ID 1438473, 11 pages, 2020.

[37] S. Salimi, P. Bahemmat, and M. Haghpanahi, "Study on residual stresses caused by underwater friction stir welding: FE modeling and ultrasonic measurement," Proceedings of the Institution of Mechanical Engineers Part E Journal of Process Mechanical Engineering, vol. 233, no. 1, pp. 118-137, 2019.

[38] Y. X. Qiao, Z. H. Tian, X. Cai et al., "Cavitation erosion behaviors of a nickel-free high-nitrogen stainless steel," Tribology Letters, vol. 67, no. 1, pp. 1-9, 2019.

[39] J. R. Nataraj, "Finite element analysis of dissimilar welding between newly developed Cr-free nickel based welding electrode and stainless steel AISI 304," International Journal of Research in Engineering and Technology, vol. 2, pp. 130-135, 2013.

[40] T. Gray, D. Camilleri, and N. McPherson, Control of Welding Distortion in Thin-Plate Fabrication, Woodhead Publishing Limited, Cambridge, 1st edition, 2014.

[41] V. N. Vapnik, The Nature of Statistical Learning Theory, Springer-Verlag, New York,NY, 1995.

[42] V. Kecman, Learning and Soft Computing: Support Vector Machines, Neural Networks, and Fuzzy Logic Models, MIT Press, Cambridge, Massachusetts, 2001.

[43] J. Kennedy and R. Eberhart, "Particle swarm optimization," in Icnn95-international Conference on Neural NetworksIEEE.

[44] Q. Huang, J. Mao, and Y. Liu, "An improved grid search algorithm of SVR parameters optimization," in 14th IEEE International Conference on Communication TechnologyIEEE. 